\title{
Review
}

\section{Self-Control and Exercise: A Review of the Bi-Directional Relationship}

\author{
Ruth Boat* and Simon B. Cooper \\ Department of Sport Science, Sport, Health and Performance Enhancement (SHAPE) Research Centre, \\ School of Science and Technology, Nottingham Trent University, UK
}

\begin{abstract}
Self-control has been defined as the mental capacity of an individual to alter, modify, change or override their impulses, desires, and habitual responses. In this review, we will discuss the bi-directional nature of the relationship between self-control and exercise. In brief, higher levels of trait self-control have been associated with greater exercise performance and adherence; whilst the depletion of state self-control has been shown to decrease performance and persistence on subsequent exercise tasks requiring self-control. In the opposite direction, long-term participation in exercise (and improved physical fitness) has been demonstrated to enhance self-control. Furthermore, an acute bout of exercise has been shown to enhance subsequent self-control, particularly when the exercise is of a moderate intensity and requires some degree of cognitive engagement. Throughout, when discussing each of these relationships, evidence will be drawn from other aspects of the review, where appropriate, to enhance our understanding of the observed effects. Finally, recommendations for future research will be made; including the importance of considering the bi-directional nature of the relationship, given that this has implications for our understanding of both self-control and exercise performance and adherence.
\end{abstract}

Keywords: Executive function, self-regulation, physical performance, ego depletion, strength model of self-control, shifting priorities model

\section{INTRODUCTION}

Executive functions refer to cognitive processes involved in the coordination and control of goaldirected behavior [1]. Executive function is vital across several life domains and is critical for academic performance in young people, workplace performance in adults, sporting performance, and the maintenance of an ability to perform the activities of daily living in older adults [2]. Executive function consists of three main domains; working memory, inhibitory control and cognitive flexibility [3]. Thus, inhibitory control is a key component of executive function and is defined as an individual's ability to inhibit their impulses and natural, habitual, or

\footnotetext{
*Correspondence to: Ruth Boat, Department of Sport Science, School of Science and Technology, Clifton Campus, Nottingham Trent University, Clifton Lane, Nottingham, NG11 8NS, UK. Tel.: +0044 1158 483596; E-mail: Ruth.Boat@ntu.ac.uk.
}

dominant behavioral responses to stimuli, in order to select a more appropriate behavior that is consistent with completing their goals [3]. More specifically, self-control has been defined as the mental capacity of an individual to alter, modify, change, or override, his or her impulses, desires, and habitual responses [4]. Such conflict is subjectively aversive and can lead people to inhibit or supress one set of responses and replace them with the second set [5]. Self-control is understood to be applied when an individual opts to inhibit their immediate desires and to replace them with behavior that aligns with their long-term goals [6]. For instance, individuals may experience conflict between two valued distal goals (e.g., a student who is trying to lose weight deciding between an important exam revision tutorial and a gym session) or two proximal desires (e.g., eat an unhealthy cake or an alcoholic drink after training), however, it is only when a proximal desire conflicts with a distal 
goal that the significant cognitive disruption associated with self-control occurs [7, 8]. Examples of this would be suppressing the desired response to eat cake when one has a long-term goal of weight loss, or overcoming the desire to relax on the sofa in favour of following a planned exercise training program to support a long-term goal of weight loss.

A limitation of work examining self-control (particularly with respect to exercise), is that there are limited behavioral tests of self-control and thus a reliance either on cognitive tasks that target inhibitory control as a surrogate marker of self-control (e.g. the Stroop test [9]), or self-report questionnaire approaches [10]. However, an emerging body of work has begun to examine the brain regions that are involved in self-control. A full review of the underpinning neuroscience of self-control is beyond the scope of this present review (the interested reader should refer to Heatherton \& Wagner [11] for a more detailed overview). However, in brief, successful self-control is reliant upon the pre-frontal cortex exhibiting topdown control over other subcortical areas, such as those involved in emotion and reward [11], with much of this work being based upon studies examining the control of addictive behaviors [12] and prejudice [13]. To date, such work has not been conducted in an exercise setting.

In recent years there has been increased interest in the relationship between exercise and self-control, with researchers from a social psychology setting primarily investigating the effects of self-control on exercise adherence and performance [14, 15], whilst researchers from a cognitive psychology and sport science perspective investigating the effects of exercise on self-control, as a component of executive function [e.g. 16]. It has been commented that these related areas of enquiry have rarely overlapped, whilst there is huge potential for each discipline to learn from the other [17]. The purpose of this brief review is therefore to discuss the bi-directional nature of the relationship between self-control and exercise, and to provide recommendations for future research to integrate these concepts.

\section{THE EFFECT OF SELF-CONTROL ON EXERCISE}

\section{Trait self-control and exercise}

Dispositional (trait) self-control has been defined as the general capacity to alter one's responses to achieve a desired state or outcome that otherwise would not arise naturally [18, 19]. In general, the ability to control oneself is considered a particularly stable individual characteristic that is related to a vast number of behaviors [10]. Individuals with high self-control are better able to control their thoughts, regulate their emotions, and inhibit their impulses, compared to people with low self-control [20]. They also enjoy better psychological wellbeing, experience higher levels of achievement and performance, and better interpersonal relationships [10, 21, 22]. High self-control is relevant to nearly all forms of behavior that contribute to a successful and healthy life; therefore, it has become a pertinent concept in numerous areas of psychological research [20].

The empirical evidence discussed above supports a positive association between self-control and a wide range of behaviors, which has also been applied to exercise performance and adherence [23-25]. For instance, anticipating and developing plans to overcome exercise barriers [26], generating exercise plans and schedules [27], and managing exercise related pain and discomfort are essential determinants of exercise adherence. Individuals with high self-control are more likely to exhibit these behaviors and, accordingly, are more likely to adhere to exercise programmes than those with low self-control [14]. Participants with high levels of self-control spent more time exercising and lost more weight (after controlling for baseline differences) during a 12-week weight loss programme [28]. Furthermore, those individuals who lack self-control may make inappropriate decisions whilst making choices regarding the achievement of their goals in stressful situations [29]. For instance, being busy at work and lack of time can become an obstacle to maintaining a physically active lifestyle and may challenge an exerciser's ability to self-regulate their exercise behaviors. Therefore, self-control is important to ensure consistent exercise participation to achieve the goals established by the individual in stressful situations [30]. Ultimately, self-control appears to be an important factor for exercise participation and adherence [31-33].

\section{State self-control and exercise}

In addition to the trait perspective on self-control, a more recent approach has emphasised that exerting self-control on one task, impairs performance on subsequent, ostensibly unrelated tasks requiring self-control [22]. This idea forms the basis of the strength model of self-control [34]. According to this theory, performance on tasks requiring self-control 
draws energy from a general resource $[35,36]$. This resource is limited and is consumed by use; therefore, it is vulnerable to becoming depleted over time [35]. Accordingly, after initial acts of effortful control, an individual's capacity to exert further self-control becomes exhausted, leading to decreased performance on subsequent acts of self-control [22]. The state of self-control resource depletion has been termed 'ego depletion' [35]. Typically, evidence for the ego-depletion effect has employed a sequentialtask paradigm [34]. In these studies, participants are randomly assigned to an experimental (self-control) condition whereby both tasks require self-control, or a control (non-self-control) condition, whereby only the second task requires self-control while the first task does not require any, or very little, self-control [35]. A meta-analysis of 198 studies reported that, in the condition where self-control is depleted during the first task (compared to no or limited self-control depletion), self-control is reduced during the second task [22].

Despite popularity and support for strength model, it has received some major challenges. A multi-lab replication failed to evidence the hypothesized reduction in self-control [37], which has led to plentiful commentaries, analyses, and debates [e.g., 38-40], suggesting that it may be too early to conclude whether the effect is an experimental or statistical artefact [39]. Furthermore, the identification of the resource that is depleted remains elusive. Glucose has been suggested as the candidate resource; initial studies reported that performing a task requiring self-control led to a reduction in blood glucose concentration, resulting in performance decrements on subsequent measures of self-control [41]. In addition, consuming a glucose drink has been shown to restore performance during cognitive tasks that require selfcontrol [41, 42]. However, recent studies have failed to replicate these effects [43-45]. For instance, in exercise research, consuming a glucose-based drink did not moderate the effects of self-control depletion on subsequent endurance performance [15]. When combined with other lines of criticism [e.g., 46], it seems unlikely that glucose is the central resource that underlies self-control.

Given the challenges associated with the popular resource model, alternative explanations as to why self-control is reduced following prior exertion have been suggested. An alternative perspective is the shifting priorities model of self-control, which is centred on motivational and attentional processes $[6,47]$. According to this model, a subjective 'val- uation' process leads to decrements in self-control, whereby alterations to distal and proximal choice evaluations occur [48]. That is, following the use of self-control, the value of exerting further selfcontrol diminishes, while the value of giving in to the tempting impulse increases [49]. Ultimately, selfcontrol represents a decision to apply effort to resist a tempting goal in favour of a distal goal [6]. This valuation process can be influenced by a number of motivational inputs. For instance, proximal choices are usually more immediately satisfying and enjoyable, compared to distal goals [6, 50]. However, distal goals that are autonomous (i.e., freely chosen and of personal meaning) [51] are less likely to be affected by proximal temptations [52], are perceived as being easier to pursue [53], and are less fatiguing [54], compared to non-concordant goals. In the contexts of exercise performance, motivational inputs that may influence the valuation process include physiological sensations of discomfort and the exercise environment (e.g., number of people in the gym).

Irrespective of the different explanations, considerable evidence exists that performance on subsequent exercise tasks is reduced following an initial task requiring self-control. For example, recreationally active participants exposed to a self-control depletion manipulation generated lower levels of work during a 10 minute cycling task, and planned to exert less effort during an upcoming exercise bout, compared to control participants [14]. Furthermore, the completion of a number of self-control tasks (e.g., supressing emotions during an upsetting movie, counting backwards from 1000 in multiples of seven whilst holding a spirit level, completing an incongruent Stroop task) has resulted in reductions in subsequent performance during press-up tasks, cycling performance, persistence at a wall-sit task, and endurance handgrip performance [15, 55-57].

\section{THE EFFECT OF EXERCISE ON SELF-CONTROL}

It is clear from the above that self-control affects adherence to performing exercise in a chronic setting, as well as exercise performance and persistence when it is depleted in the acute setting. The second aspect of the bi-directional relationship between self-control and exercise is the effect that performing exercise has on self-control. As mentioned earlier, self-control, a key aspect of inhibitory control, is one of three core aspects of executive function. Given the crucial role 
that executive function has to play in determining academic performance in young people, workplace performance in adults, sporting performance, and the maintenance of an ability to perform the activities of daily living in older adults [2], it is unsurprising that it is the one of the most commonly measured cognitive domains in the exercise-cognition literature [16]. This section of the review will focus on both the acute and chronic effects of exercise on self-control, a key component of executive function.

Before examining the literature, it is important to consider how self-control has been assessed in the exercise-cognition literature. The most common test used to assess self-control is the Stroop test [9], and in particular the colour-interference (commonly referred to as the 'incongruent' or 'complex' level). In this instance, a participant must use their selfcontrol to inhibit the natural response of responding by selecting the word, but respond by selecting the colour of the font that the word is written in. For example, if the word 'red' was written in green ink, the correct response would be green. Evidence from neuroimaging studies supports that the colour interference level of the Stroop task requires activation of the pre-frontal cortex [58], which as discussed earlier is the key brain region involved in self-control [11]. It should be noted that when using the Stroop test, both the response time and accuracy should be recorded as outcome variables, to ensure that any change in one outcome cannot be explained by a compensatory change in the other (i.e. a speed-accuracy tradeoff). Interestingly, the Stroop test is also the most commonly used method to assess and deplete selfcontrol in the studies mentioned above, considering the effect of acute self-control depletion on exercise performance.

\section{Chronic effect of exercise on self-control}

When examining the chronic effects of exercise on self-control, much of the evidence is cross-sectional in nature and considers the relationship between physical fitness (most commonly cardio-respiratory fitness) and self-control [59-61]. In addition to the potential for confounding variables to affect the findings in cross-sectional evidence of this nature, the inferences made in this relationship rely on the assumption that chronic participation in exercise elicits improvements in physical fitness, and thus use physical fitness as a surrogate marker of chronic participation in exercise. Overall, the weight of evidence suggests that higher levels of physical fitness are asso- ciated with enhanced self-control in young people [59], adults [60], and older adults [61].

A higher quality of evidence for a causal relationship between chronic participation in exercise and self-control comes from intervention studies. There is evidence that such interventions enhance self-control. An improvement in self-control, as assessed by the Stroop test, has been shown in young people following $20 \mathrm{~min}$ of exercise per day over 8 weeks [62], and older adults following $3 \times 60 \mathrm{~min}$ exercise sessions per week for 3 months [63] and 10 months of aerobic training [64]. However, in these studies, it is not possible to isolate the effects of participation in exercise from the concurrent improvement in physical fitness that is likely to arise as a result of such participation in exercise, therefore, the exact mechanisms driving these effects warrant further investigation.

\section{Acute effect of exercise on self-control}

A substantial amount of literature suggests that an acute bout of exercise enhances self-control, as indicated by improved performance on the Stroop test (for review see [16]). This effect has been demonstrated across numerous populations, including young people at school [65], adults [66, 67] and older adults [68, 69]. These effects are of interest as enhanced Stroop test performance (reflecting enhanced self-control and, more broadly, executive function) is hypothesised to improve academic achievement in young people, workplace performance in adults, and assist with ameliorating the age-related decline typically seen in older adults. However, the exercise-cognition literature is confounded by a mediating effect of exercise characteristics on this relationship, such as the intensity, duration, and modality of exercise performed [70].

Although discrepancies do exist in the literature, it is generally believed that there is an inverted-U relationship between exercise intensity and the cognitive benefits that are gained. For instance, moderate intensity exercise provides the greatest benefit, whereas low intensity exercise does not elicit a sufficient stimulus to have an effect, and high intensity exercise may be too exhausting. Meta-analytical approaches to reviewing the literature confirm this trend [16, 71]. Another important factor to consider however is the time course of the acute effects of exercise on state self-control and how this may interact with exercise intensity. For example, some evidence suggests that moderate intensity exercise may enhance self-control immediately following exercise, 
whilst the effects of higher intensity exercise are more delayed, with effects seen up to 1-hour post-exercise [16]. These effects may be explained by the strength model of self-control [34]. For instance, vigorous intensity exercise may use more of the limited central resource. This is because individuals may have to control their cognitive, emotional, and motor processes, as well as their behavioral tendencies [72]. Moreover, individuals may be required to 'dig deep' and resist feelings of pain and discomfort during high intensity exercise. As a result, individuals may have a reduced self-control capacity immediately following high intensity exercise, resulting in deteriorations in performance on the Stroop test. An alternative explanation can also be made using the shifting priorities model [47], whereby vigorous intensity exercise results in a shifting of attention to the proximal goal (e.g. to complete the Stroop task as quickly as possible due to feelings of exercise-induced fatigue), relative to the distal goal (e.g. optimal performance on the Stroop task), resulting in more errors on the cognitive task. However, studies directly comparing the effect of different exercise intensities on self-control, the time course of these effects and the mediating mechanisms, are lacking in the literature and this area warrants further investigation.

In addition to the intensity of exercise, it is also important to consider the modality of exercise. Much of the work to date examining the effect of different exercise modalities has been conducted in young people, with the work in adult populations generally focussing on prolonged, moderate intensity exercise. It has been suggested that cognitively engaging exercise may be particularly beneficial in adolescent populations [65,73], an effect not observed in younger children [74]. This could again be explained by the strength model of self-control [34], in that as young people age their cognitive abilities develop and subsequently, so does the size of their "limited resource'; thus adolescents can cope with combined physical and cognitive exertion, whereas this is too challenging for younger children and hence deleterious effects are observed.

An interesting potential avenue for future research is to examine how the acute effects of a single bout of exercise on self-control may be affected by habitual physical activity levels (and physical fitness). Some preliminary evidence suggests that an acute bout of exercise may be particularly beneficial for self-control in higher fit adolescents when compared to their lower fit counterparts [65]. Using the aforementioned strength model [34] to explain these effects, it is possible that lower fit adolescents have a smaller 'resource' to draw upon (as discussed above, where higher physical fitness was demonstrated to enhance self-control). In games-based activity, the lower fit adolescents will also be working at a higher relative exercise intensity than their higher fit counterparts, thus depleting their self-control resources to a greater extent. However, evidence in this area is newly emerging and certainly warrants further investigation.

To conclude, overall an acute bout of exercise has been demonstrated to have a small but positive effect on self-control, as evidenced by the effect size of 0.25 for the Stroop test interference effect in the metaanalysis of Chang et al. [16]. However, important mediators in this relationship, such as the participant (e.g., age, cognitive development, fitness) and exercise (e.g., intensity, duration, modality) characteristics must be considered.

\section{CONCLUSION}

We have presented evidence of the bi-directional nature of the relationship between self-control and exercise. As has been demonstrated in each section of this review, research to date has typically considered only one aspect of this relationship. However, we feel that each of these relationships should be viewed with respect to each other; given that each of these have implications for both self-control and exercise performance and adherence. In addition, this review has discussed two key theoretical models (the strength model of self-control and the shifting priorities model) that have been proposed to explain why the exertion of self-control reduces subsequent exercise performance and persistence. We have also suggested that these proposed models can be applied to help explain the effect of exercise on subsequent self-control.

The bi-directional nature of the relationship between self-control and exercise gives rise to a number of potential research questions, which could be incorporated in to future work in this area. These include, but are by no means limited to, the following:

- We have demonstrated that an acute bout of exercise elicits a beneficial effect on subsequent self-control post-exercise. However, does this acute improvement also lead to an improvement in trait self-control?

- We have also demonstrated that the depletion of self-control negatively impacts upon exercise 
performance and persistence in subsequent tasks requiring self-control. Given the bi-directional nature of the relationship that we have considered, can we use this knowledge to further examine the mechanisms responsible for mediating the effects of self-control depletion on exercise performance and persistence, which are currently poorly understood?

- Does an individual's baseline level of selfcontrol influence the effect of subsequent bouts of exercise? For example, does an individual with greater trait self-control see a greater or lesser improvement in state self-control following moderate intensity exercise; and does an individual's baseline level of self-control impact upon the exercise performance decrements seen following acute self-control depletion?

- Is trait or state self-control more important for exercise adherence? i.e. is trait self-control a key determinant of adherence to an exercise programme; or is it state self-control in each individual setting which determines whether an individual undertakes an exercise training session; or a combination of both?

\section{REFERENCES}

[1] Titz C, Karbach J. Working memory and executive functions: Effects of training on academic achievement. Psych Res. 2014;78(6):852-68. doi: 10.1007/s00426-013-0537-1

[2] Eslinger PJ, Flaherty C. Executive functions and behavior across the lifespan. In Rizzo M, Anderson S, Fritzsch B, editors. The Wiley Handbook on the Aging Mind and Brain. New York: Wiley; 2018. pp. 235-269. doi: 10.1002/9781118772034.ch13

[3] Diamond A. Executive functions. Annu Rev Psychol. 2013;64:135-68. doi: 10.1146/annurev-psych-113011143750

[4] Baumeister RF, Heatherton TF. Self-regulation failure: An overview. Psychol Inq. 1996;7(1):1-15. doi: 10.1207/s15327965pli0701_1

[5] Inzlicht M, Bartholow BD, Hirch JB. Emotional foundations of cognitive control. Trends Cogn Sci. 2015;19(3):126-32. doi: 10.1016/j.tics.2015.01.004

[6] Milyavskaya M, Inzlicht M. Attentional and motivational mechanisms in self-control. In De Ridder, D, Adriaanse M, Fujita K, editors. Handbook of self-control in health and well-Being. New York: Routledge; 2016.

[7] Katobe HP, Hoffman W. On integrating the components of self-control. Perspect Psychol Sci. 2015;10(5):618-38. doi: 10.1177/1745691615593382

[8] Taylor IM, Boat R, Murphy SL. A broader theoretical consideration of self-control and athletic performance. Int Rev Sport Exerc Psychol. 2018. doi: 10.1080/1750984X.2018.1480050

[9] Stroop JR. Stroop test. J Exp Psychol. 1935;18:622-43.

[10] Tangney JP, Baumeister RF, Boone AL. High self-control predicts good adjustment, less pathology, better grades, and interpersonal success. J Pers. 2004;72(2):271-324. doi: 10.1111/j.0022-3506.2004.00263.x

[11] Heatherton TF, Wagner DD. Cognitive neuroscience of selfregulation failure. Trends Cog Sci. 2011;15(3):132-9. doi: 10.1016/j.tics.2010.12.005

[12] Volkow ND, Fowler JS, Wang GJ, Telang F, Logan J, Jayne M, Ma Y et al. Cognitive control of drug craving inhibits brain reward regions in cocaine abusers. Neuroimage. 2010;49(3):2536-43. doi: 10.1016/j.neuroimage. 2009.10.088

[13] Richerson JA, Baird AA, Gordon HL, Heatherton TF, Wiland CL, Trawalter S, Shelton JN. An fRMI investigation of the impact of interracial contact on executive function. Nat Neurosci. 2003;6(12):1323-8. doi: 10.1038/ nn1156

[14] Martin Ginis KA, Bray SR. Application of the limited strength model of self-regulation to understanding exercise effort, planning and adherence. Psychol Health. 2011;25(10):1147-60. doi: 10.1080/08870440903111696

[15] Boat R, Taylor IM, Hulston CJ. Self-control exertion and glucose supplementation prior to endurance performance. Psychol Sport Exerc. 2017;29(1):103-10. doi: 10.1016/j.psychsport.2016.12.007

[16] Chang YK, Labban JD, Gapin JJ, Etnier JL. The effects of acute exercise on cognitive performance: A meta-analysis. Brain Res. 2012;1453:87-101. doi: 10.1016/j.brainres.2012.02.068

[17] Hofman W, Schmeichel BJ, Baddeley AD. Executve functions and self-regulation. Trends Cog Sci. 2012;16(3):17480. doi: 10.1016/j.tics.2012.01.006

[18] Bauer IM, Baumeister RF. Self-regulatory strength. In Vohs KD, Baumeister RF, editors. Handbook of self-regulation: Research, theory and applications. New York: Guilford Press; 2011. pp. 64-82.

[19] Baumeister RF, Vohs KD. Self-regulation, ego depletion, and motivation. Soc Personality Psychol Compass. 2007;1(1):115-28.

[20] De Ridder DTD, Lensvelt-Mulders G, Finkenauer C, Stok MF, Baumeister RF. Taking stock of self-control: A metaanalysis of how trait self-control relates to a wide range of behviours. Pers Soc Psychol Rev. 2012;16(1):76-99. doi: $10.1177 / 1088868311418749$

[21] Gailliot MT, Baumeister RF. Self-regulation and sexual restraint: Dispositionally and temporarily poor selfregulatory abilities contribute to failures at restraining sexual behavior. Pers Soc Psychol Bull. 2007;33(2):17386.

[22] Hagger MS, Wood C, Stiff C, Chatzisarantis NLD. Ego depletion and the strength model of self-control: A meta-analysis. Psychol Bull. 2010;136(4):495-525. doi:10.1037/a0019486

[23] Audiffren M, Andre N. The exercise-cognition relationship: A virtuous circle. J Sport Health Sci. 2019;8(4):339-47. doi: 10.1016/j.jshs.2019.03.001

[24] Buckley J, Cohen JD, Kramer AF, McAuley E, Mullen SP Cognitive control in the self-regulation of physical activity and sedentary behaviour. Front Hum Neurosci. 2014;8:747. doi: 10.3389/fnhum.2014.00747

[25] Butryn ML, Martinelli MK, Remmert JE, Roberts SR, Zhang F, Forman E, Manasse SM. Executive functioning as a predictor of weight loss and physical activity outcomes. Ann Behav Med. 2019;53(10):909-17. doi: 10.1093/abm/kaz001

[26] Sniehotta FF, Scholz U, Schwarzer R. Action plans and coping plans for physical exercise: A longitudinal 
intervention study in cardiac rehabilitation. $\mathrm{Br} \mathrm{J}$ Health Psychol. 2006;11(1):23-37. doi: 10.1348/135910705X 43804

[27] Arbour-Nicitopoulos KP, Martin Ginis KA, Latimer AE. Planning, leisure-time physical activity, and coping selfefficacy in persons with spinal cord injury: A randomized control trial. Int J Phys Med Rehabil. 2009;90(12):2003-11. doi: 10.1016/j.apmr.2009.06.019

[28] Crescioni W, Ehrlinger J, Alquist JL, Conlon K, Baumeister $\mathrm{R}$, Schatschneider $\mathrm{C}$, Dutton GR. High trait selfcontrol predicts positive health behaviors and success in weight loss. J Health Psychol. 2011;16(5):750-9. doi: 10.1177/1359105310390247

[29] Lewinsohn S, Mano H. Multi-attribute choice and affect: The influence of naturally occurring and manipulated moods on choice processes. J Behav Decis Mak. 1993;6(1):33-51. 1993. doi: 10.1002/bdm.3960060103

[30] Ahn J, Jeon H, Kwon S. Associations between selfregulation, exercise participation, and adherence intention among Korean university students. Percep Mot Skills. 2016;123(1):324-40. doi: 10.1177/0031512516659874

[31] Dishman RK, Jackson AS, Bray MS. Self-regulation of exercise behavior in the TIGER study. Ann of Behav Med. 2014;48(1):80-91. doi: 10.1007/s12160-0139573-8

[32] Gerber M, Lindwall M, Brand S, Lang C, Elliot C, Puhse U. Longitudinal relationships between perceived stress, exercise self-regulation and exercise involvement among physically active adolescents. J Sports Sci. 2015;33(4):36980. doi: 10.1080/02640414.2014.946072

[33] Stadler G, Oettingen G, Gollwitzer PM. Physical activity in women: Effects of a self-regulation intervention. Am J Prev Med. 2008;36(1):29-34. doi: 10.1016/j.amepre. 2008.09.021

[34] Baumeister RF, Vohs KD, Tice DM. The strength model of self-control. Curr Dir Psychol Sci. 2007;16(x):351-5. doi: 10.1111/j.1467-8721.2007.00534

[35] Baumeister RF, Bratslavsky E. Muraven M, Tice DM. Ego depletion: Is the active self a limited resource? J Pers Soc Psychol. 1998;74(5):1252-65. doi: 10.1037/00223514.74.5.1252(1998)

[36] Muraven M, Collins RL, Shiffman S, Paty JA. Daily fluctuations in self-control demands and alcohol intake. Psychol Addict Behav. 2005;19(2):140-7. doi: 10.1037/0893164X.19.2.140

[37] Hagger MS, Chatzisarantis NLD, Alberts H, Anggono $\mathrm{CO}$, Batailler C, Birt AR et al. A multilab preregistered replication of the ego-depletion effect. Pers Psych Sci. 2016;11(4):546-73. doi: 10.1177/1745691616652873

[38] Baumeister RF, Vohs KD. Misguided effort with elusive implications. Pers Psych Sci. 2016;11(4):574-5. doi: $10.1177 / 1745691616652878$

[39] Blazquez D, Botella J, Suero M. The debate on the ego-depletion effect: Evidence from meta-analysis with the p-uniform method. Front Psych. 2017;8:197. doi: 10.3389/fpsyg.2017.00197

[40] Hagger MS, Chatzisarantis NLD. Commentary: Misguided effort with elusive implications, and sifting signal from noise with replication science. Front Psych. 2016;7:621. doi: 10.3389/fpsyg.2016.00621

[41] Gailliot MT, Baumeister RF, DeWall CN, Mayner JK, Plant EA, Tice, DM, Brewer LE, et al. Self-control relies on glucose as a limited energy source: Willpower is more than a metaphor. J Pers Soc Psychol. 2007;92(2):325-36. doi: 10.1037/0022-3514.92.2.325
[42] De Wall CN, Baumeister RF, Gailliot MY, Mayner JK Depletion makes the heart grow less helpful: Helping as a function of self-regulatory energy and genetic relatedness. Pers Soc Psychol Bull. 2008;34(12):1653-62. doi: $10.1177 / 0146167208323981$

[43] Lange F, Eggert F. Sweet delusion. Glucose drinks fail to counteract ego-depletion. Appetite. 2014;75:54-63. doi: 10.1016/j.appet.2013.12.020

[44] Lange F, Seer C, Rapior M, Rose J, Eggert F. Turn it all you want: Still no effect of sugar consumption on ego-depletion. J Europ Psych Stud. 2014;5(3):1-8. doi:10.5334/jeps.cc

[45] Molden DC, Hui, CM, Scholer AA, Meier BP, Norwen, EE, D'Agostino PR, Martin V. Motvational versus metabolic effects of carbohydrate on self-control. Psychol Sci. 2012;23(10):1137-44. doi: 10.1177/0956797612439069

[46] Kurzban R. Does the brain consume additional glucose during self-control tasks. Evol Psychol. 2010;8(2): 244-59.

[47] Inzlicht M, Schmeichel BJ. Beyond limited resources: Selfcontrol failure as the product of shifting priorities. In Vohs K, Baumeister R, editors. Handbook of Self-Regulation. New York: Guilford Press; 2012.

[48] Berkman E, Livingston JL, Kahn LE, Inzlicht M. (September 25, 2015) Valuation as a Mechanism of Self-Control. Available from: SSRN: http://ssrn.com/abstract=2665823

[49] Kool W, Botvinick M. A labour/leisure trade off in cognitive control. J Exp Psychol Gen. 2014;143(1):131-41. doi: 10.1037/a0031048

[50] Kahneman D, Tversky A. Prospect theory: An analysis of decision under risk. Econometric. 1979;47(2):263-92.

[51] Deci EL, Ryan RM. Motivation, personality, and development within embedded social contexts: An overview of self-determination theory. In Ryan RM, editor. Oxford handbook of human motivation. Oxford: Oxford University Press; 2012. pp. 85-107.

[52] Milyavskaya M, Inzlicht M, Hope N, Koestner R. Saying 'No' to temptation: 'want-to' motivation improves selfregulation by reducing temptation rather than by increasing self-control. J Pers Soc Psychol. 2015;109(4):677-93. doi: 10.1037/pspp0000045

[53] Werner KM, Milyavskaya M, Foxen-Craft E, Koestner R. Some goals just feel easier: Self-concordance leads to goal progress through subjective ease, not effort. Pers Indiv Dif. 2016;96(1):237-42. doi: 10.1016/j.paid.2016.03.002

[54] Moller AC, Deci EL, Ryan RM. Choice and ego-depletion: The moderating role of autonomy. Pers Soc Psychol Bull. 2014;40(2):1024-36. doi: 10.1177/0146167206288008

[55] Boat R, Taylor IM. Prior self-control exertion and perceptions of pain during a physically demanding task. Psychol Sport Exerc. 2017;33(1):1-6. doi: 10.1016/j. psychsport.2017.07.005

[56] Bray SR, Graham JD, Martin Ginis KA, Hicks AL. Cognitive task performance causes impaired maximal force production in human hand flexor muscles. Biol Psychol. 2011;89(1):195-200. doi: 10.1016/j.biopsycho. 2011.10.008

[57] Dorris DC, Power DA, Kenefick E. Investigating the effects of ego depletion on physical exercise routines of athletes. Psychol Sport Exerc. 2012;13(2):118-25. doi: 10.1016/j.psychsport.2011.10.004

[58] Miyake A, Friedman NP, Emerson, MJ, Witzki AH, Howerter A. The unity and diversity of executive functions and their contributions to complex "frontal lobe" tasks: A latent variable analysis. Cog Psychol. 2000;41:49-100. doi: 10.1006/cogp.1999.0734 
[59] Buck SM, Hillman CH, Castelli DM. The relation of aerobic fitness to Stroop task performance in preadolescent children. Med Sci Sports Exerc. 2008;40:166-72. doi: 10.1249/mss.0b013e318159b035

[60] Chang YK, Chi L, Etnier JL, Wang CC, Chu CH, Zhou C. Effect of acute aerobic exercise on cognitive performance: Role of cardiovascular fitness. Psychol Sport Exerc. 2014;15(5):464-70. doi: 10.1016/j.psychsport.2014.04.007

[61] Weinstein AM, Voss MW, Prakash RS, Chaddock L, Szabo A, White SM et al. The association between aerobic fitness and executive function is mediated by prefrontal cortex volume. Brain Beh Immunity. 2012;26(5):811-9. doi: 10.1016/j.bbi.2011.11.008

[62] Ludyga S, Gerber M, Brand S, Puhse U, Colledge F. Effects of aerobic exercise on cognitive performance among young adults in a higher education setting. Res Quart Sport Exerc. 2018;89(2):164-72. doi: 10.1080/02701367.2018.1438575

[63] Predovan D, Fraser SA, Renaud M, Bherer L. The effect of three months of aerobic training on Stroop performance in older adults. J Aging Res. 2012;269815. doi: $10.1155 / 2012 / 269815$

[64] Smiley-Oyen AL, Lowry KA, Francois SJ, Kohut ML, Ekkekakis P. Exercise, fitess, and neurocognitive function in older adults: The 'selective improvement' and 'cardiovascular fitness' hypotheses. Ann Behav Med. 2008; 36(3):280-91.

[65] Cooper SB, Dring KJ, Morris JG, Sunderland C, Bandelow S, Nevill ME. High intensity intermittent games-based activity and adolescents' cognition: Moderating effect of physical fitness. BMC Pub Health. 2018;18:603. doi: 10.1186/s12889-018-5514-6

[66] Sibley BA, Etnier JL, Le Masurier GC. Effects of an acute bout of exercise on cognitive aspects of Stroop performance. J Sport Exerc Psych. 2006;28(3):285-9. doi: 10.1123/jsep.28.3.285
[67] Chang YK, Etnier JL. Effects of an acute bout of localized resistance exercise on cognitive performance in middle-aged adults: A randomized controlled trial study. Psychol Sport Exerc. 2009;10:19-24. doi: 10.1016/j.psychsport.2008.05.004

[68] Barella LA, Etnier JL, Chang YK. The immediate and delayed effects of an acute bout of exercise on cognitive performance of healthy older adults. J Aging Phys Act. 2010;18:87-98

[69] Hyodo K, Dan I, Suwabe K, Kyotuku Y, Yamada Y, Akahori $\mathrm{M}$ et al. Acute moderate exercise enhances compensatory brain activation in older adults. Neurobiol Aging. 2012;33(11):2621-32. doi: 10.1016/j.neurobiolaging. 2011. 12.022

[70] Williams RA, Hatch L, Cooper SB. A review of factors effecting the acute exercise-cognition relationship in children and adolescents. Int Comp Med. 2019;4(3). doi: 10.21926/obm.icm.1903049

[71] McMorris T, Hale BJ. Differential effects of differing intensities of acute exercise on speed and accuracy of cognition: A meta-analytical investigation. Brain Cogn. 2012;80:33851. doi: 10.1016/j.bandc.2012.09.001

[72] Wagstaff CRD. Emotion regulation and sport performance. J Sport Exerc Psychol. 2014;36:401-12. doi: 10.1123/jsep.2013-0257

[73] Pesce C, Crova C, Cereatti L, Casella R, Bellucci M. Physical activity and mental performance in preadolescents: Effects of acute exercise on free-recall memory. Ment health Phys Act. 2009;2:16-22. doi: 10.1016/j.mhpa.2009.02.001

[74] Gallotta MC, Guidetti L, Franciosi E, Emerenziani GP, Bonavolonta V, Baldari C. Effects of varying type of exertion on children's attention capacity. Med Sci Sports Exerc. 2012;44(3):550-5. doi: 10.1249/MSS.0b013e3182305552 